\title{
42-Year-Old Patient With Severe COVID-19 Pneumonia and Cytokine Storm: Hurdles During Management
}

\author{
Maksudul Islam Mazumder ${ }^{1}$, Sumaiya Akter ${ }^{2}$, Halima Sadia ${ }^{3}$, Ishrat Binte Reza ${ }^{4}$, M Zahir Uddin5, \\ HAM Nazmul Ahasan ${ }^{6}$
}

\begin{abstract}
:
A middle aged man presented with fever for 14 days, dry cough for 10 days and shortness of breath for 6 days. He tested positive for RT-PCR for COVID-19 on $5^{\text {th }}$ day of illness. Patient was maintaining home isolation until he developed shortness of breath. After hospitalization patient was treated with standard dose of Remdesivir, dexamethasone and antibiotics. But his oxygen demand was increasing day by day. Inflammatory markers including serum ferritin, CRP level was also increasing. Patient was having a cytokine storm. At this point of treatment anti IL6 Tocilizumab was being considered. But patient's wellbeing was improved and tocilizumab was not given. Our patient gradually recovered from severe COVID-19 pneumonia and cytokine storm without tocilizumab.
\end{abstract}

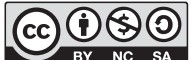

DOI: https://doi.org// 0.3329/jom.v2 Ii2.50219

Copyright: (C) 2020 Mazumder Ml et al. This is an open access article published under the Creative Commons Attribution-NonCommercial-NoDerivatives 4.0 International License, which permits use, distribution and reproduction in any medium, provided the original work is properly cited, is not changed in any way and it is not used for commercial purposes.

Received: 08 August 2020;

Accepted: 17 August 2020

\section{Introduction:}

The clinical presentation of COVID-19 is highly heterogeneous, ranging from asymptomatic to severe pneumonia with respiratory failure that could lead to invasive mechanical ventilation or death. ${ }^{1}$ The disease is characterized by an initial phase of viral replication that can be followed by a second phase driven by the host inflammatory response. ${ }^{2}$ The most critical patients can develop a so-called cytokine storm, characterized by increased production of many cytokines that produce long-term damage and lung tissue fibrosis. ${ }^{3}$ No therapy has been approved for COVID-19 pneumonia, but current clinical approaches consider the combination of antiviral drugs and immunomodulatory

1. Registrar, Medicine Department, Popular Medical College Hospital, Dhanmondi, Dhaka

2. Assistant Registrar, Medicine Department, Popular Medical College Hospital, Dhanmondi, Dhaka

3. Assistant Registrar, Medicine Department, Popular Medical College Hospital, Dhanmondi, Dhaka

4. Assistant Professor, Medicine Department, Popular Medical College Hospital, Dhanmondi,

5. Professor, Medicine Department, Popular Medical College Hospital, Dhanmondi, Dhaka

6. Professor, Medicine Department, Popular Medical College Hospital, Dhanmondi, Dhaka

Address of Correspondence: Dr. Md. Maksudul Islam Mazumder, Flat E4, 474, Vertex Tower, Amtola Mosjid Road, Shahjahanpur, Dhaka. Email: fuad.mmch@yahoo.com drugs. Various methods of immunomodulation are being quickly examined, in order to blunt the hyperinflammation caused by cytokine release. Interleukin (IL) inhibitors, Janus kinase inhibitors, and interferons are just a few of the drugs that are in clinical trials. ${ }^{4,5}$

Cytokine release syndrome is common in patients with COVID-19, and elevated serum IL-6 correlates with respiratory failure, ARDS, and adverse clinical outcomes. Elevated serum C-reactive protein (CRP), a protein whose expression is driven by IL-6, is also a biomarker of severe betacoronavirus infection. ${ }^{6,7}$

Tocilizumab is approved for the treatment of rheumatoid arthritis, polyarticular juvenile idiopathic arthritis, systemic juvenile idiopathic arthritis, giant cell arteritis, and chimeric antigen receptor T cell-induced cytokine release syndrome.IL6 inhibitor tocilizumab, is part of several randomized, doubleblind, placebo-controlled phase 3 clinical trials (REMDACTA, COVACTA, EMPACTA) to evaluate the safety and efficacy of tocilizumab plus standard of care in hospitalized adult patients with severe COVID-19 pneumonia. The trials did not meet primary endpoint of improved clinical status in patients with COVID-19-associated pneumonia but did show a positive trend in time to hospital discharge.As of June 2020, the NIH guidelines note insufficient data to recommend for or against use of IL-6 inhibitors.

Here we are going to describe a case with confirmed COVID19 severe pneumonia with cytokine storm and problems we faced during management. 


\section{Case Summary:}

A 42-year-old man presented with complaints of fever for more than two weeks, dry cough for 10 days and shortness of breath for 5 days. His fever was low grade, mostly evening rising which subsided after taking paracetamol. Short bouts of cough was nonproductive and associated with chest heaviness. 5 days prior presenting to us he noticed difficulty in breathing. Patient had no previous illness or comorbidities. Along with these symptoms patient also developed extreme weakness, malaise and occasional passage of loose stool.

As he developed symptoms, he did necessary investigations including RT-PCR for COVID-19 from nasal swab prior presenting to us. He tested positive for COVID-19. He was maintaining isolation at home with symptomatic remedies until he developed shortness of breath. At home he took oral antibiotic (amoxyclav) and oral dexamethasone (10 mg per day for 5 days). But as patient noticed gradual drop in self monitored oxygen saturation ( $\mathrm{SpO} 2$ below 90 ) by pulse oxymeter and also persisting fever, he decided to get hospitalized. During presentation patient was anxious, dyspnoeic (respiratory rate

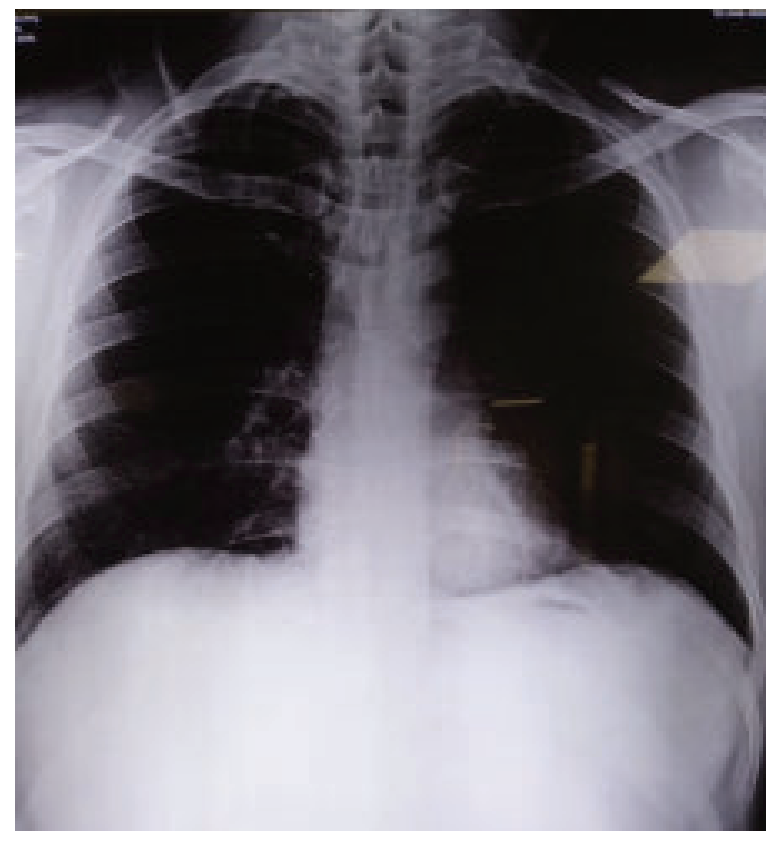

CXR done on $6^{\text {th }}$ day of disease 28/min), pulse 110/min, BP 110/65 $\mathrm{mmHg}$, temperature 100 degree F, SpO2 88\% without oxygen.

After hospitalization patient was being treated with IV amoxyclav and moxifloxacin, IV dexamethasone 10mg 12 hourly, low molecular weight heparin along with antipyretic drug. Oxygen saturation was maintained around $92 \%$ with $5 / 6$ liter oxygen by face mask initially. Patient's clinical parameters were being monitored regularly along with biochemical parameters and chest radiology.

Patient's investigation reports which were done 5 days prior admission were unremarkable. Repeated tests done during hospitalization showed an increasing trend of inflammatory markers. On $1^{\text {st }}$ day of admission his total WBC was 29 X $10^{9} /$ 1 with $90 \%$ neutrophil, 4\% lymphocyte, $108 \mathrm{~mm}$ ESR. CRP was $273 \mathrm{mg} / \mathrm{L}$, Serum ferritin was $3086 \mathrm{ng} / \mathrm{ml}$, D dimer 0.1, procalcitonin $0.09 \mu \mathrm{g} / \mathrm{l}$, serum lactate $31.5 \mathrm{mmol} / \mathrm{l}, \mathrm{LDH}$ $763 \mathrm{U} / \mathrm{L}$. Chest X-ray showed inhomogenous opacity involving whole right lung and lower part of left lung. Renal function, hepatic function tests were normal. Blood culture revealed no growth.

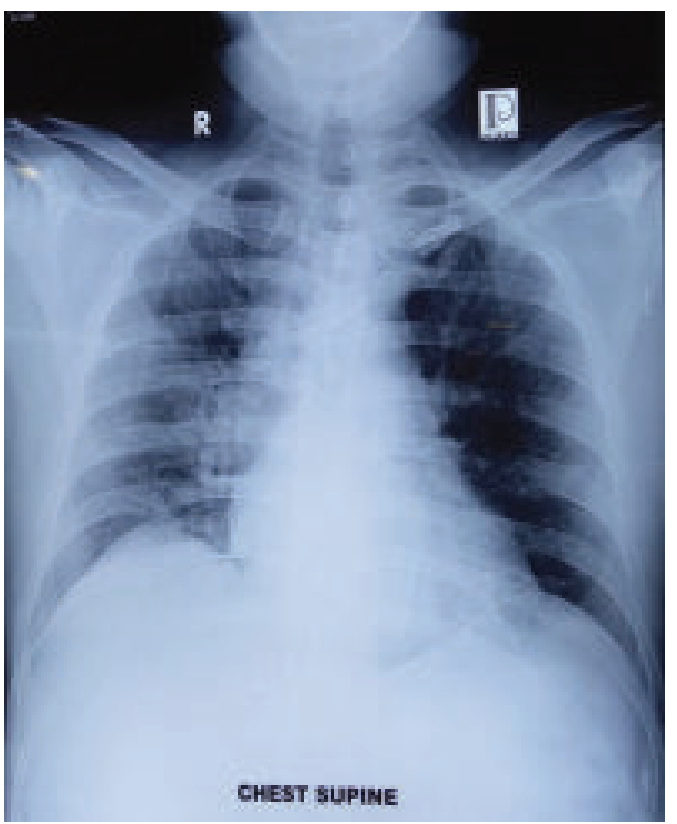

CXR done on $14^{\text {th }}$ day of disease

\begin{tabular}{|c|c|c|c|c|c|c|c|}
\hline$\overline{\text { Date }}$ & $\begin{array}{c}\text { WBC } \\
\left(\mathrm{X} 10^{9} / \mathrm{L}\right)\end{array}$ & $\begin{array}{c}\text { Neutrophil }(\%) \\
\text { Lymphocute }(\%)\end{array}$ & $\begin{array}{c}\text { Serum } \\
\text { Ferritin }(\mathrm{ng} / \mathrm{ml})\end{array}$ & $\begin{array}{c}\text { D dimer } \\
\text { level }(\mathrm{ng} / \mathrm{ml})\end{array}$ & $\begin{array}{c}\text { CRP } \\
(\mathrm{mg} / \mathrm{l})\end{array}$ & $\begin{array}{l}\mathrm{LDH} \\
(\mathrm{U} / 1)\end{array}$ & $\begin{array}{l}\text { Procalcitonin } \\
(\mu \mathrm{g} / \mathrm{l})\end{array}$ \\
\hline$\overline{29 / 7 / 20}$ & 5.2 & $\begin{array}{l}70 \\
24\end{array}$ & & & & & \\
\hline $2 / 8 / 20$ & 29 & $\begin{array}{c}90 \\
4\end{array}$ & 2049.35 & 0.1 & 274 & 763 & 0.09 \\
\hline $3 / 8 / 20$ & 29.64 & $\begin{array}{c}85 \\
5\end{array}$ & 3086.43 & 0.27 & 81 & 747 & 0.06 \\
\hline $5 / 8 / 20$ & 21 & $\begin{array}{l}80 \\
10\end{array}$ & 5551 & 0.1 & 19 & 641 & 0.05 \\
\hline
\end{tabular}


Initial HRCT of chest done prior admission on $6^{\text {th }}$ day of illness showed scattered ground glass densities in all lobes of the left lung, mainly peripheral distribution. HRCT of chest was repeated on 5 th day of hospitalization $\left(16^{\text {th }}\right.$ day of symptom onset) which revealed bilateral extensive ground glass lesions, consolidations with intra and interlobular septal thickening as well as crazy paving lesion-suggestive of severe COVID-19 pneumonia with around $80 \%$ involvement OFCT favoring peak stage of disease.

Patient became afebrile after 2 days but his oxygen demand was high. Saturation of oxygen was maintained to $94 \%$ with 15 liter oxygen with non-re-breather face mask. So, Remdesivir was started on $3^{\text {rd }}$ day of admission and antibiotic was changed to meropenem. Despite everything, patient's oxygen demand remained high and though CRP and D-dimer level were decreasing, serum ferritin level reached $5551 \mathrm{ng} /$ $\mathrm{ml}$ on $3^{\text {rd }}$ admission day. Meanwhile patient's wellbeing was much improved. A consideration of initiating Anti IL6 Tocilizumab was being considered.

But as patient's wellbeing was improved and considering risk of overwhelming secondary infection, Tocilizumab was not given. Gradually patient's oxygen demand decreased, and inflammatory markers were also reduced. On $14^{\text {th }}$ day of hospital admission patient was doing fine without oxygen and was discharged.

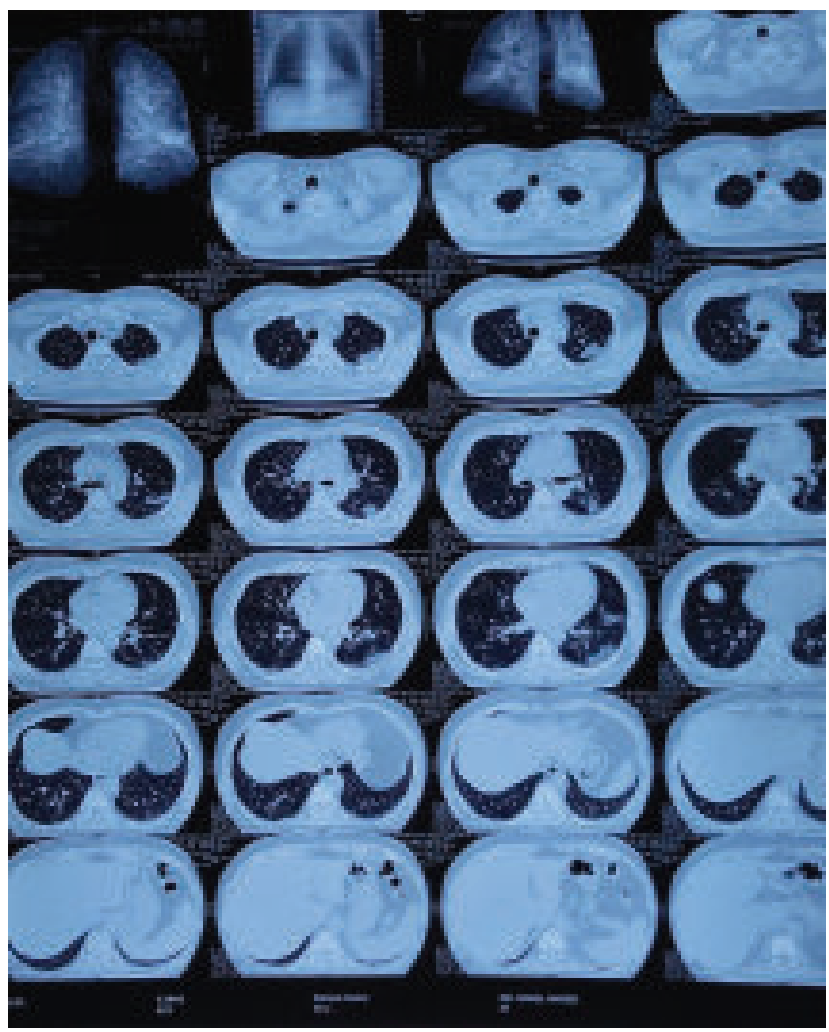

HRCT chest on $16^{\text {th }}$ day of disease

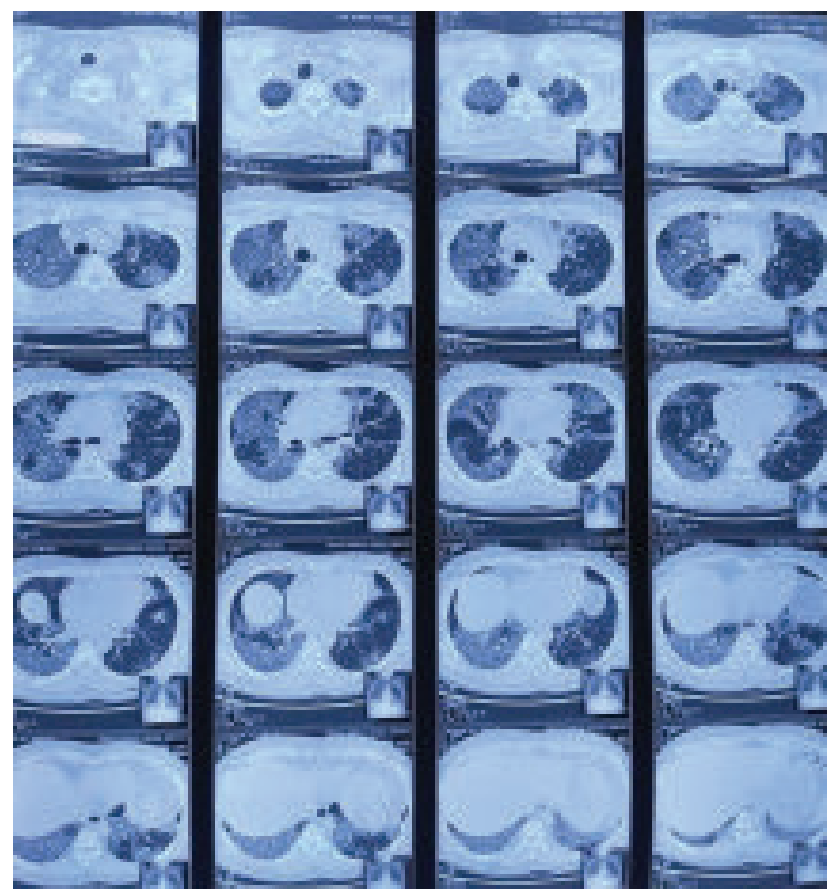

HRCT chest on $6^{\text {th }}$ day of disease

\section{Discussion:}

ARDS is the leading cause of mortality in COVID-19 patients and extensive release of pro-inflammatory cytokines is suspected to contribute to poor outcomes in some patients. ${ }^{8}$ Elevated pro-inflammatory cytokines and inflammatory biomarkers such as interleukin 6, C-reactive protein (CRP), and ferritin have been shown to be higher in patients with severe COVID-19 and predictors of mortality. ${ }^{9}$ Tocilizumab, a monoclonal antibody against interleukin 6 receptor, was previously approved by Food and Drug Administration for the treatment of cytokine release syndrome and may provide clinical benefit for selected COVID-19 patients with high inflammatory biomarkers. ${ }^{10}$

Our patient was suffering from severe COVID-19 pneumonia with HRCT chest showing $80 \%$ lung involvement. In the course of his illness raised inflammatory markers were noted. Particularly ferritin level reached more than 5000. His high oxygen demand, tachypnea, high inflammatory markers all made him a good candidate for anti IL6 therapy. But during last week of illness despite high inflammatory markers and high oxygen demand, patient's wellbeing was improved. Considering patient's clinical condition, a balanced decision was taken considering current cytokine storm and risk of secondary infection due to tocilizumab. The patient was gradually improved. During discharge, patient was afebrile, normal respiratory rate, oxygen saturation $95 \%$ without oxygen. All biochemical parameters were within normal limit. 
Through this case we might learn to focus on clinical condition of the patient in COVID-19. Though several study has shown effectiveness of IL-6 inhibitor tocilizumab in severe COVID-19 infection, physicians must consider its effectiveness and balance the side effects.

\section{References:}

1. Zhou F, Yu T, Du R, et al. Clinical course and risk factors for mortality of adult inpatients with COVID-19 in Wuhan, China: a retrospective cohort study. Lancet 2020; 395: 105462.

2. Guan W-J, Ni Z-Y, Hu Y, et al. Clinical characteristics of coronavirus disease 2019 in China. N Engl J Med 2020; 382: 1708-20.

3. Pedersen SF, Ho Y-C. SARS-CoV-2: a storm is raging. J Clin Invest 2020; 130: 2202-05

4. Stebbing J, Phelan A, Griffin I, et al. COVID-19: combining antiviral and anti-inflammatory treatments. Lancet Infect Dis 2020; 20: 400-02.
5. Ingraham NE, Lotfi-Emran S, Thielen BK, Techar K, Morris RS, Holtan SG, et al. Immunomodulation in COVID19. Lancet Respir Med. 2020 May 4.

6. G. Chen et al. J. Clin. Invest. 137244 (2020)

7. Q. Ruan, K. Yang, W. Wang, L. Jiang, J. Song, Intensive Care Med. 10.1007/s00134-020-05991-x (2020).

8. Mehta P. McAuley D.F. Brown M. etal.COVID-19: consider cytokine storm syndromes and immuno-suppression. Lancet. 2020; 395 (-4): 103

9. Ruan Q. Yang K.WangW.JiangL.Song J.Clinical predictors of mortality due to COVID-19 based on an analysis of data of 150 patients from Wuhan, China.Intensive Care Med. 2020; (published online on March 3).

10. Le R.Q. Li L. Yuan W. etal.FDA approval summary: tocilizumab for treatment of chimeric antigen receptor $T$ cellinduced severe or life-threatening cytokine release syndrome. Oncologist. 2018; 23: 943-947 